\title{
Echocardiographic detection of subvalvar aortic root aneurysm extending to mitral valve annulus as complication of aortic valve endocarditis
}

\author{
B E GRIFFITHS, * M C PETCH, T A H ENGLISH \\ From the Departments of Cardiology and Cardiothoracic Surgery, Papworth Hospital, Papworth Everard, \\ Cambridge
}

SUMMARY Acute aortic regurgitation as a consequence of infective endocarditis developed in a young man after peritonitis. A large subvalvar aortic root aneurysm extending to the mitral valve annulus together with features of severe acute aortic regurgitation were shown by $\mathrm{M}$-mode echocardiography. The echocardiographic findings were confirmed at operation when obliteration of the aneurysmal space and aortic valve replacement were performed. Postoperative echocardiography confirmed obliteration of the aneurysmal space.

Subvalvar aortic aneurysms initially thought to be of congenital origin and virtually confined to African Negroes may occur as a complication of aortic valve endocarditis..$^{-5}$ Until recently subvalvar aortic aneurysms could only be detected preoperatively by aortography. Recent case reports have shown that these aneurysms may be detected by $\mathbf{M}$-mode echocardiography. ${ }^{6^{-8}}$ The subvalvar aneurysms detected, however, did not extend to the mitral valve annulus and only in one case could endocarditis be definitely implicated as the cause.

Mycotic aneurysms involving the region of the left ventricular outflow tract are an indication for early surgical treatment. In the present case $M$-mode echocardiography clearly showed the subvalvar aneurysm extending to the mitral valve annulus. This finding was confirmed at operation. Careful $\mathrm{M}$-mode echocardiography provides a non-invasive means of diagnosing these aneurysms in the critically ill patient without resorting to cardiac catheterisation.

\section{Case report}

A 19-year-old student with no previous cardiovascular history was admitted to a hospital in Amsterdam with acute peritonitis. An emergency laparotomy showed a perforated appendix and $500 \mathrm{ml}$ pus was drained from the abdominal cavity. Despite antibiotic treatment with gentamycin, metronidazole, and carbenicillin a

^Present address: Department of Cardiology, Welsh National School of Medicine, Heath Park, Cardiff. grumbling fever persisted. Eleven days later a second laparotomy was performed and two large abscess cavities in the left subphrenic space and pouch of Douglas were found. The abscess cavities were drained and antibiotic therapy continued until his discharge. Two days later he was admitted to Papworth Hospital with increasing shortness of breath and night sweats. On admission he was severely ill in pulmonary oedema and with cardiovascular signs of severe acute aortic regurgitation. He was afebrile and had no stigmata of infective endocarditis. Blood cultures remained sterile. Echocardiography disclosed a large echo-free space posterior to the posterior aortic wall (Fig. 1A) extending to the mitral valve annulus (Fig. 1B). Presystolic mitral valve closure indicated severe acute aortic regurgitation ${ }^{9}$ (Fig. 2A). Open heart surgery was performed three weeks after his admission to Papworth Hospital and 10 weeks after his initial presentation with acute appendicitis. A large subaortic annular aneurysm was found between the aortic annulus anteriorly and the left atrium posteriorly. The mouth of the aneurysm occupied an area from the middle of the non-coronary sinus to the middle of the left coronary sinus and buried downwards and posteriorly leading to detachment of the mitral valve annulus. The aneurysmal sac contained infected granulations. The aortic valve was tricuspid with a large perforation in the non-coronary cuspthe prime cause of the regurgitation. A strip of pericardium was used to line the outflow tract of the left ventricle and the mitral valve was reattached. The aneurysm was obliterated by interrupted sutures and 

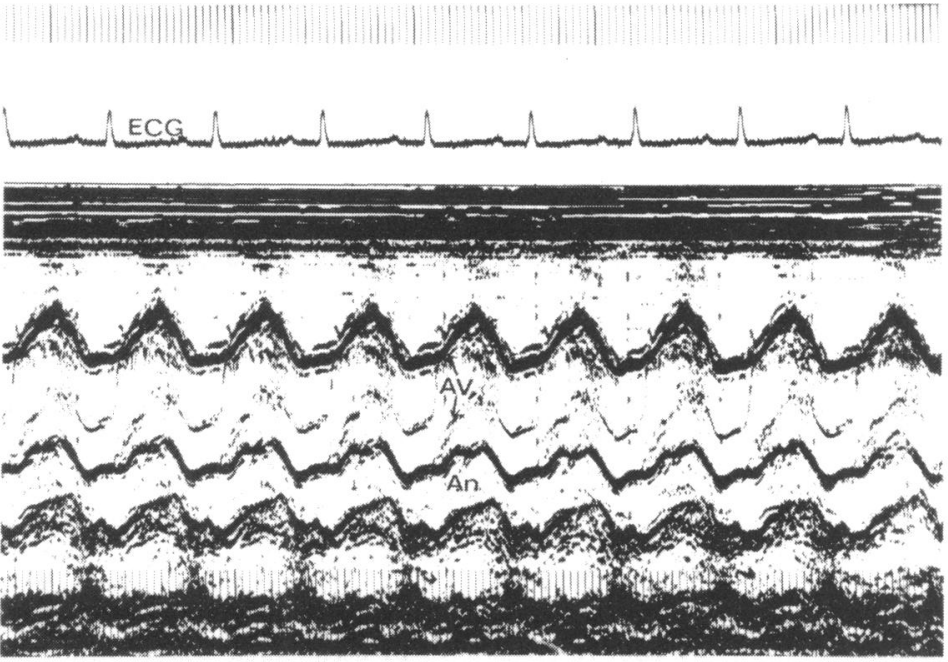

(A)

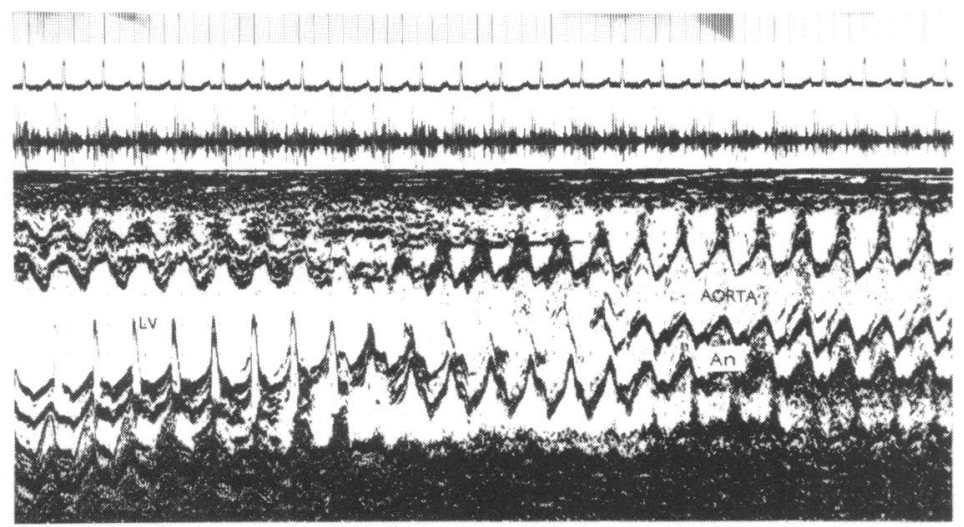

(B)
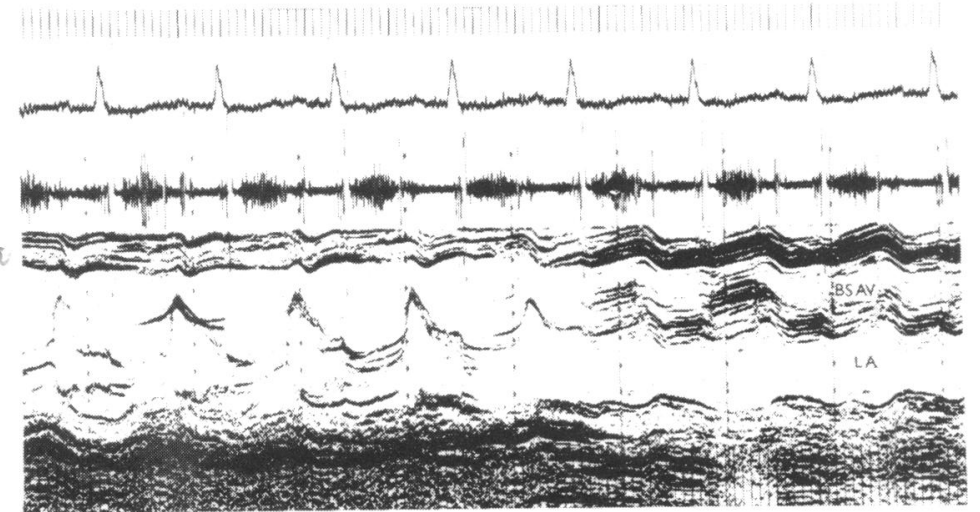

(C)
Fig. 1(A) Preoperative

echocardiogram of aorta and aortic valve showing a large aneurysm ( $A n)$ as an echo-free space posterior to the aorta and anterior to the left atrium. The aneurysm expands in late diastole and early systole and narrows in early diastole.

(B) Preoperative echocardiogram LV aorta scan illustrating the posterior aneurysm extending to the mitral valve annulus. Vigorous contraction of the septum and left ventricular posterior wall suggests severe aortic regurgitation.

(C) Postoperative echocardiogram $L V$ aorta scan showing obliteration of the aneurysmal space, with thickening of the posterior wall secondary to fibrosis within the obliterated aneurysm. $A V$, aortic valve; $L V$, left ventricle; $B S A V$, Björk-Shiley aortic valve; $L A$, left atrium. 
the aortic valve excised and replaced with a No. 21 Björk-Shiley prosthesis.

Postoperative echocardiography confirmed obliteration of the aneurysmal space (Fig. 1C) with thickening of the posterior aortic wall secondary to thrombosis and fibrosis within the obliterated aneurysm and normalisation of mitral valve closure (Fig. 2B). The patient has subsequently remained well but with residual haemodynamically insignificant mitral and aortic regurgitation.

\section{Discussion}

Subvalvar aortic aneurysms initially considered congenital in origin and virtually confined to African Negroes are now a recognised complication of infective endocarditis and may be encountered in up to $10 \%$ of patients undergoing aortic valve replacement for aortic valve endocarditis. ${ }^{1-510}$ Trauma is another precipitating cause. ${ }^{11}$ The special problems and surgical treatment involved in such patients have been discussed by Gonzalez-Lavin et al. ${ }^{10}$ The left ventricular outflow tract is a region of strategic importance. ${ }^{12}$ Here the mitral-aortic intervalvular fibrosa connects the part of the aortic root related to the non-coronary and left coronary aortic valve cusps to the base of the anterior mitral valve leaflet. Wedged between the aorta and adjacent left atrium and extending to the intervalvular fibrosa is epicardial tissue-the epicardial wedge. Infection from the aortic valve may therefore spread directly to the epicardial wedge which itself has little resistance to infection because of its relative avascularity ${ }^{13}$ and thus lead to aneurysm formation. ${ }^{14}$ Infection may similarly extend to the anterior mitral valve leaflet. Because of this particular anatomical relation infection may reach the mitral valve in another way. The anterior mitral valve leaflet lies immediately subjacent to the aortic valve and may become secondarily infected by regurgitation of blood through an actively infected aortic valve-the "jet lesion". 1516

Pneumococcal and staphylococcal infections are the

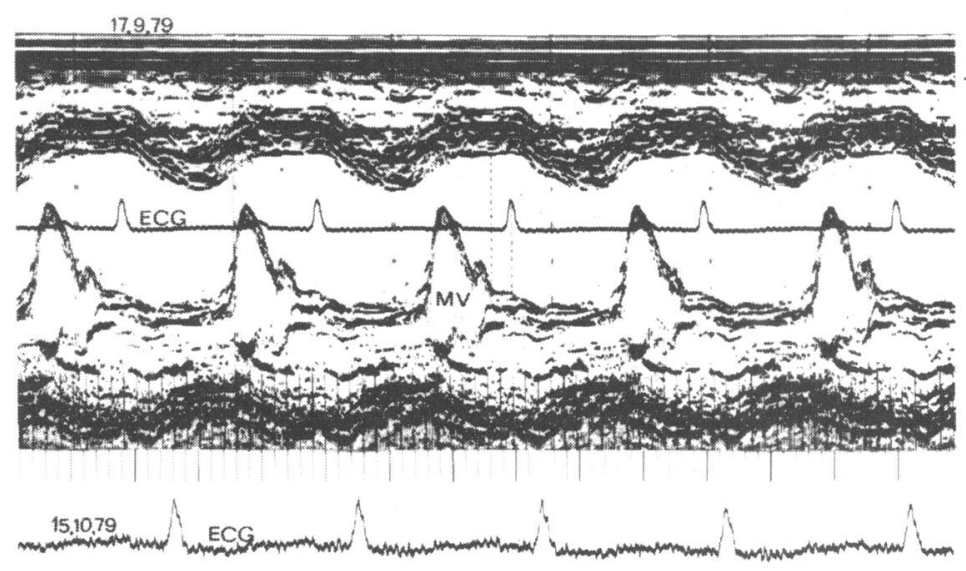

Fig. 2(A) Preoperative echocardiogram of the mitral valve showing almost complete closure of the mitral valve 60 ms before the inscription of the QRS complex of a simultaneously recorded electrocardiogram.

(B) Postoperative echocardiogram of the mitral valve showing normalisation of mitral valve closure after the inscription of the QRS complex of a simultaneously recorded electrocardiogram. ECG, electrocardiogram; PHONO, phonocardiogram; $M V$, mitral valve.

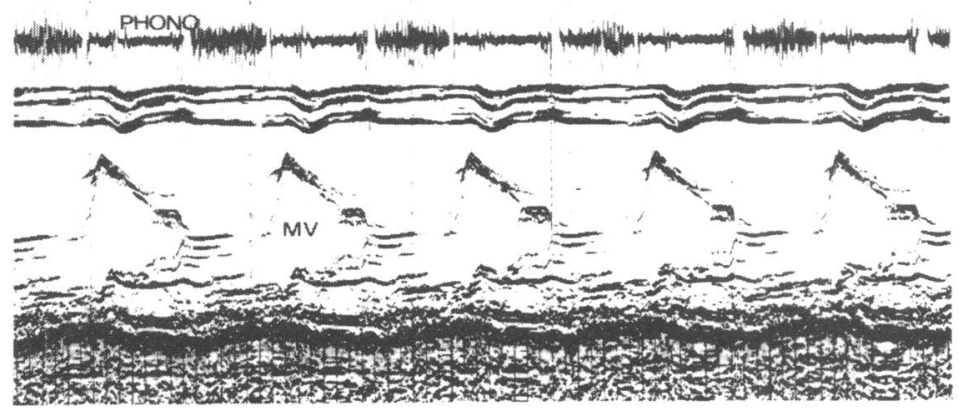


most common organisms, ${ }^{5}$ though cases secondary to fungi ${ }^{10} 17$ and Brucella suis ${ }^{18}$ infection have been reported. Indeed, Brucella suis was implicated in the first recorded case of a subannular aneurysm secondary to infection. ${ }^{18}$

These aneurysms may calcify, 810 thrombose, and subsequently embolise, ${ }^{19}$ extend and rupture into a chamber of the right heart, ${ }^{4}$ lead to aortic regurgitation secondary to distortion of the aortic valve, ${ }^{6}$ rupture into the pericardium with subsequent death because of haemopericardial tamponade, 142021 extend to the mitral valve annulus with detachment of the mitral valve, ${ }^{10}$ or extend to the interventricular septum. ${ }^{7}$ Their presence usually indicates early surgical referral and treatment.

Until recently aortography was the only means of establishing preoperative diagnosis. Despite a recent paper disputing the dangers of cardiac catheterisation in patients with infective endocarditis, ${ }^{22}$ cardiac catheterisation is not without its risks when performed in acutely ill patients with aortic valve endocarditis. ${ }^{23-25} \mathrm{~A}$ non-invasive method of diagnosing these aneurysms is clearly desirable.

Three recent case reports have shown the usefulness of M-mode echocardiography in the detection of subannular aneurysms. ${ }^{6-8}$ In none of these reported cases, however, did the detected aneurysm extend to the mitral valve annulus and a recent infective process (Staph. aureus) could only be implicated in one case. ${ }^{7}$

The differential diagnosis of the echocardiographic features described includes a sinus of Valsalva aneurysm of the non-coronary sinus-a possible complication of infective endocarditis. A congenital sinus of Valsalva aneurysm would be extremely unlikely as they are confined almost exclusively to the right coronary sinus ${ }^{26}$ and would occupy a position anterior to the anterior aortic wall. ${ }^{27}$ In this case the diagnosis of infective endocarditis can be in no doubt: the development of acute regurgitation after a prolonged febrile episode, and the presence of infective granulations containing degenerative cocci in the aneurysm support the diagnosis.

Preoperative echocardiography detected the large annular aneurysm and its extension to the mitral valve annulus. Echocardiography also clearly showed the severity of the aortic regurgitation, with features of left ventricular volume overload and presystolic closure of the mitral valve. Cardiac catheterisation was not performed in this ill young man. The echocardiographic findings were confirmed at operation.

We conclude that M-mode echocardiography may provide valuable information in patients with severe aortic valve endocarditis and may show subannular aortic aneurysms when present. Careful echocardiography may obviate the need for cardiac catheterisation in the critically ill patient.

\section{References}

1 Abrahams DG, Barton CJ, Cockshott WP, Edington GM, Weaver EJM. Annular subvalvular left ventricular aneurysms. $Q \mathcal{f}$ Med 1962; 31: 345-60.

2 Chesler E, Joffe N, Schamroth L, Meyers A. Annular subvalvular left ventricular aneurysms in the South African Bantu. Circulation 1965; 32: 43-51.

3 Hatcher CR Jr, Symbas PN, Logan WD Jr, Abbot OA. Surgical aspects of endocarditis of the aortic root. $A m \mathcal{F}$ Cardiol 1969; 23: 192-8.

4 Hudson REB. Infective endocarditis. Aneurysms. In: Cardiovascular pathology. London: Edward Arnold, 1965; 2: 1208-10.

5 Sheldon WH, Golden A. Abscesses of the valve rings of heart, frequent but not well-recognised complication of acute bacterial endocarditis. Circulation 1951; 4: 1-12.

6 Alter BR, Treasure RL, Martin HA, Humphrey SH, Murgo JP, McGranahan GM Jr. Echocardiographic detection of a subannular aortic aneurysm. Am Heart $\mathcal{f}$ 1978; 96: 525-8.

7 Fox S, Kotler MN, Segal BL, Parry W. Echocardiographic diagnosis of acute aortic valve endocarditis and its complications. Arch Intern Med 1977; 137: 85-9.

8 Gaasch WH, Cleveland RJ. Echocardiographic examination in aortic regurgitation: subaortic aneurysm and flail aortic leaflet. Chest 1976; 70: 771-3.

9 Botvinick EH, Schiller NB, Wickramasekaran R, Klausner SC, Gertz E. Echocardiographic demonstration of early mitral valve closure in severe aortic insufficiency. Its clinical implications. Circulation 1975; 51: 836-47.

10 Gonzalez-Lavin L, Scappatura E, Lise M, Ross DN. Mycotic aneurysms of the aortic root. A complication of aortic valve endocarditis. Ann Thorac Surg 1970; 9: 55161.

11 Waldhausen JA, Petry EL, Kurlander GJ. Successful repair of subvalvular annular aneurysm of the left ventricle. $N$ Engl f Med 1966; 275: 984-7.

12 Gross L, Kugel MA. Topographic anatomy and histology of the valves in the human heart. Am F Pathol 1931; 7: 445-74.

13 Ryon DS, Pastor BH, Myerson RM. Abscess of the myocardium. Am f Med Sci 1966; 251: 698-705.

14 Chesler E, Korns ME, Porter GE, Reyes CN, Edwards JE. False aneurysm of the left ventricle secondary to bacterial endocarditis with perforation of the mitralaortic intervalvular fibrosa. Circulation 1968; 37: 518-23.

15 Edwards JE. Mitral insufficiency secondary to aortic valvular bacterial endocarditis. Circulation 1972; 46: 623-6.

16 Gonzalez-Lavin L, Lise M, Ross D. The importance of the "jet lesion" in bacterial endocarditis involving the left heart. F Thorac Cardiovasc Surg 1970; 59: 185-92.

17 Mershon JC, Samuelson DR, Layman TE. Left ventricular "fibrous body" aneurysm caused by aspergillus endocarditis. Am f Cardiol 1968; 22: 281-5.

18 Layman TE, January LE. Mycotic left ventricular aneurysm involving the fibrous atrioventricular body. Am f Cardiol 1967; 20: 423-7.

19 Chesler E, Tucker RBK, Barlow JB. Subvalvular and apical left ventricular aneurysms in the Bantu as a source of systemic emboli. Circulation 1967; 35: 1156-62.

20 Medalia LS, Drapiewski JF. Congenital defect of the 
aortic vestibule complicated by bacterial endocarditis with perforation and death from cardiac tamponade, report of case. Am Heart $\mathcal{f}$ 1946; 31: 103-6.

21 Pirani CL. Erosive (mycotic) aneurysm of the heart with rupture. Arch Pathol 1943; 36: 579-86.

22 Welton DE, Young JB, Raizner AE, et al. Value and safety of cardiac catheterization during active infective endocarditis. Am f Cardiol 1979; 44: 1306-10.

23 Ellis $\mathrm{K}$, Jaffe C, Malm JR, Bowman FO Jr. Infective endocarditis: roentgenographic considerations. Radiol Clin North Am 1973; 11: 415-42.

24 Gleckman $R$. Culture negative bacterial endocarditis confirming the diagnosis. Am Heart $\mathcal{F}$ 1977; 94: 125-6.
25 Sutton R, Petch MC, Parker J. Echocardiography in infective endocarditis (abstract). Br Heart $\mathcal{f}$ 1976; 38: 312 .

26 Jones AM, Langley FA. Aortic sinus aneurysms. Br Heart f 1949; 11: 325-41.

27 Rothbaum DA, Dillon JC, Chang S, Feigenbaum $\mathrm{H}$. Echocardiographic manifestation of right sinus of Valsalva aneurysm. Circulation 1974; 49: 768-71.

Requests for reprints to Dr B E Griffiths, Department of Cardiology, Welsh National School of Medicine, Heath Park, Cardiff CF4 4XN.

\section{Notice}

Subacute bacterial endocarditis

A survey is currently being carried out by the British Cardiac Society and the Medical Services Study Group of the Royal College of Physicians. Though improvement of dental prophylaxis is one objective, the survey is already yielding other valuable information. It is hoped that proformas will be received in respect of a high proportion of patients with subacute bacterial endocarditis in the British Isles seen during 1981 and 1982 and readers are asked to arrange for them to be submitted in respect of any cases that come to their notice. Proformas can be obtained from Sir Cyril Clarke, Medical Services Study Group, King's Fund Centre, 126 Albert Street, London NW1 7NF (tel. 01-267 6111, ext. 263) to whom they should be returned. 